\title{
Aproximación al devenir del canapé en los interiores domésticos burgaleses del XVIII
}

\author{
Francisco José SAnz de la Higuera \\ I.E.S. "Torreblanca" (Sevilla) \\ sanzdelahiguera@gmail.com
}

Recibido: 10 de diciembre de 2010

Aceptado: 22 de junio de 2012

\begin{abstract}
RESUMEN
La presencia y permeabilidad del canapé, mueble introducido en los hogares burgaleses más progresistas y aristocráticos durante el Setecientos, indica, como sucede con la cómoda y otros mobiliarios sofisticados, una búsqueda de confort y comodidad creciente, enlazada con la modernidad llegada de Francia con la dinastía borbónica. La obtención de un elevado estatus de elegancia y notoriedad, preñada de lujo y distinción, fue característica no sólo de la nobleza más rancia sino también de las categorías socio-profesionales más "burguesas", en especial de los profesionales de las administraciones públicas, del ejercicio del derecho y de los mercaderes y militares.
\end{abstract}

Palabras clave: canapé, interior doméstico, hogar, Burgos, siglo XVIII.

\section{An Approach to the reality of the canapé at the domestic interiors in Eighteenth-Century Burgos (Spain)}

\begin{abstract}
The presence and permeability of the canapé - a piece of furniture introduced in the bourgeoisie and nobility homes of Eighteenth Century Burgos-, showed -as it happened with the chest of drawers and other sophisticated furniture-, an increasing search of comfort and commodity. This was connected with the modernity arrived to Spain from Bourbon France. The achievement of a high status of elegance, luxury and distinction, was characteristic not only of the most ancient nobility but also of the social and professional 'bourgeoisie' in the public administration, lawyers, merchants and the military.
\end{abstract}

Key words: canapé, domestic inner, household, Burgos, 18th century. 
Aunque, en puridad, no se debe hablar en España de una "revolución en el consumo" en el siglo XVIII ${ }^{1}$, lo cierto es que, desde la óptica del devenir de la mejoría de la cultura material ${ }^{2}$, en los territorios de la Corona borbónica se producen algunos avances muy significativos. Por lo tocante al mobiliario, es imprescindible significar la penetración de la cómoda y de otros muebles, nacionales o de importación ${ }^{3}$, en los interiores domésticos españoles del Setecientos ${ }^{4}$. Entre ellos descuella, con luz propia, el canapé. Ya fuera por "espíritu de imitación" o por un efervescente impulso de mejora

1 Vid., de entre la pluralidad de excelentes trabajos disponibles, las aportaciones de BerG, M.: Mercados y manufactura en Europa, Barcelona, Crítica, 1995. Brewer, J. y Porter, R. (eds.): Consumption and the World of Goods, Londres-Nueva York, Roudledge, 1993. MckendricK, N., Brewer, J. y Plumb, J. H. (eds.): The Bird of a Consumer Society. The Commercialisation of Eighteenth Century England, Bloomington, Indiana University Press, 1982. Roche, D.: Histoire des choses banales. Naissance de la consommation dans les sociétés traditionnelles (XVIIe-XIXe siècles), París, Fayard, 1997. Shammas, C.: The Preindustrial Consumer in England and America, Oxford, Figueroa Press, 2008. Weatherill, L.: Consumer behavior and material culture in Britain, 1660-1760, Londres-Nueva York, Routledge, 1988.

2 Los estudios sobre cultura material más significativos son, sin un ánimo exhaustivo y ordenados por riguroso orden alfabético, además de los señalados en la nota anterior, los propuestos por BRAUDEL, F.: Civilización material, economía y capitalismo. Siglos XV-XVIII. 1.Las estructuras de lo cotidiano, Madrid, Alianza, 1984. Franco Rubio, G.: "Sobre la cultura material a l'Espagnya del segle XVIII", Pérez SAmper, M. a A. (coord.): La vida quotidiana a través dels segles, Barcelona, Pòrtic, 2002, pp. 311-332. García Fernández, M.: "La cultura material doméstica en la Castilla del Antiguo Régimen", García fernández, M. y Sobaler SECO, M. ${ }^{a}$ A. (coords.): Estudios en homenaje al profesor Teófanes Egido, Valladolid, Gráficas Andrés Martín, 2004, pp. 249-270. GARNot, B.: La culture matérielle en France aux XVIe-XVIIe-XVIIIe siècles, París, Ophrys, 1995. Pоulot, D.: "Una nouvelle histoire de la culture matérielle?", Revue d'Histoire Moderne et Contemporaine, 44/2 (1997), pp. 344-357. Pounds, N. J. G.: La vida cotidiana. Historia de la cultura material, Barcelona, Crítica, 1999. SARTI, R.: Vida en familia. Casa, comida y vestido en la Europa Moderna, Barcelona, Crítica, 2003. Schuurman, J. A. y Walsh, L. (eds.): Material Culture: Consumption, Life-Style, Standart of Living, 1500-1900, XI International Economic History Congress, Milán, Books, 1994. Sobrado CorReA, H.: "Los inventarios post-mortem como fuente privilegiada para el estudio de la cultura material en la Edad Moderna", Hispania, 215 (2003), pp. 825-862. Torras, J. y Yun CASAlilla, B. (dirs.): Consumo, condiciones de vida y comercialización. Cataluña y Castilla, siglos XVII-XIX, Ávila, Miján, Industrias Gráficas Abulenses, 1999. Van der Woude, A. y Schuurman, J. A. (eds.): Probate inventories. A New Source for the Historical Study of Wealth. Material Culture and Agricultural Development, Utrecht, Hes Publishes, 1980.

3 Piera Miquel, M.: "La cómoda y el tocador, muebles de prestigio en la sociedad catalana del siglo XVIII", Pedralbes, 25 (2006), pp. 266-282. De la misma autora, "Cómodas y otros muebles de importación en los interiores domésticos barceloneses del siglo XVIII", en Rey CASTelao, O. y LóPez, R. (eds.): El mundo urbano en el siglo de la Ilustración, vol. I, X Reunión de la FEHM, La Coruña, 2009, pp. 371-383 y "Los artesanos del mueble en Barcelona a finales del siglo XVIII: el espacio doméstico", Nuevo Mundo Mundos Nuevos [en línea], Coloquios, 2008. Descuellan también las reflexiones de Rodríguez Bernis, S.: "Nuevas maneras, nuevos muebles", en Museu de les arts decoratives, Curso "El mueble del siglo XVIII: Nuevas aportaciones a su estudio", Barcelona, 2009, "El gesto fácil. La europeización de las maneras, entre la sociabilidad y la desenvoltura", Afrancesados y anglófilos. Las relaciones con la Europa del progreso en el siglo XVIII, Madrid, 2008 y MuÑoz-Yusta del Álamo, M.: "Tendencias del interiorismo "a la francesa" en España a finales del siglo XVIII y principios del XIX”, Afrancesas y anglófilos...Agradezco públicamente, y de manera manifiesta, a doña Sofía y a don Miguel, así como a la Fundación "Fernando de Castro", su gentileza y amabilidad por el envío, vía e-mail, de sus trabajos, de excelente calidad y aprovechamiento.

4 Vid a este respecto, entre otras, las aportaciones de Lick, R.: "Les intérieurs domestiques dans la seconde moitié du XVIIIe siècle d'après les inventaires après décès de Coutances", Annales de Normandie, 20 (1970), pp. 293-316. Rosselló Nicolau, M.: "Els interiors barcelonins de finals del segle XVIII i començaments del XIX", Locus Amoenus, 9 (2007), pp. 277-305. Sauret Guerrero, T.: "Familia e interiores burgueses. Una visión iconográfica", en Boletín de Arte, 13-14 (1992-1993), Málaga, pp. 201-209 y SAnz DE LA Higuera, F. J.: "Familia, hogar y vivienda en Burgos a mediados del siglo XVIII. Entre cuatro paredes, compartiendo armarios, camas, mesas y manteles", Investigaciones Históricas, 22 (2002), pp. 165-211. 
en el confort y la notoriedad, las viviendas se pueblan con un atrezzo decorativo y un mobiliario cada vez más sofisticado, elegante y vistoso, característico de sociedades salidas de profundos baches, el terrible y negro Siglo de Hierro, y entradas en el Siglo de las Luces, del florecimiento antes de las nuevas catástrofes del XIX.

\section{FUENTES DOCUMENTALES Y METODOLOGÍA APLICADA}

La reconstrucción de la cultura material tiene su yacimiento primigenio en el interior de los gruesos volúmenes de los protocolos notariales, en especial a través de los inventarios post-mortem (IPM en lo sucesivo). El Archivo Histórico Provincial de Burgos $^{5}$ cuenta con unos fondos documentales de gran calado para efectuar una inmersión profunda en la recreación de los interiores domésticos de la ciudad en el Antiguo Régimen y, más en concreto, en el siglo XVIII. La complementariedad de dicha fuente notarial con el Catastro elaborado a instancias del marqués de Ensenada para la implantación de la Única Contribución ${ }^{6}$, fuente eminentemente fiscal y económica, posibilita la creación de un entramado en $3 \mathrm{D}$ de las peculiaridades de sus vecinos en un período tan efervescente como mediados del Setecientos.

Por otra parte, el basamento documental y el esqueleto cuantitativo posterior tienen en el acervo bibliográfico la carne narrativa que reconstruye, ambos simultáneamente, la historia tal y como la concebimos. De entre la inmensa nómina de trabajos en que se cita la presencia en los interiores domésticos del canapé destacan, sin un ánimo exhaustivo ni de dejar marginado a nadie de una manera malintencionada, los trabajos, ordenados alfabéticamente, de Abad Zardoya, Anguita Herrador, Ayala Alonso, Bartolomé Bartolomé, Bonet Correa, Creixell Cabeza ${ }^{7}$. No menos importantes son las aportaciones de Crespo Rodríguez, Franco Rubio, García Fernández, Germaná Róquez, Junquera y Mato, Lara Betancourt, Márquez Gómez, Mateos Gil, Rodríguez Bernis, Rotaeche y Ordoez, Sampayo Seoane, Thornton ó Symonds ${ }^{8}$. Véanse

5 En lo sucesivo AHPB. Protocolos Notariales (PN) o Justicia Municipal (JM). Múltiples legajos.

6 Citado como ADPB. Catastro de Ensenada (CE). Libros 344, 345, 346, 347, 348 y 349.

7 Abad Zardoya, C.: "El estrado: continuidad de la herencia islámica en los interiores domésticos zaragozanos de las primeras Cortes borbónicas (1700-1759)", Artigrama, 18 (2003), pp. 375-392 y "La vivienda aragonesa de los siglos XVII y XVIII. Manifestaciones del lujo en la decoración de interiores", Artigrama, 19 (2004), pp. 409-425. Anguita Herrador, R.: El arte barroco español, Madrid, Encuentro, 2004, p. 23. Ayala Alonso, E.: "Cómo la casa se convirtió en hogar. Vivienda y ciudad en el México decimonónico", Scripta Nova, 146 (2003) [en línea]. Bartolomé Bartolomé, J. M.: “Comerciantes de origen castellano en León: las familias Pablos-Salán-Rodríguez y Hernández de Medina-Fernández (1700-1850)”, CIH Brocar, 28 (2004), pp. 145-166, "Burguesía comercial con orientación financiera: familias de arrendatarios de rentas de León (1750-1850)", Estudios Humanísticos, Historia, 5 (2006), pp. 211-226 y "La formación de un gran patrimonio mercantil-agrícola en León: La familia Fernández-Chicarro (1700-1850)”, Investigaciones Históricas, 26 (2006), pp. 215-236. Bonet Correa, A.: Fiesta, poder y arquitectura: aproximaciones al barroco español, Madrid, Akal, 1990, p. 112. CReixell CABezA, R. M": "Escenografías del habitar. Casa y cuerpo en la primera mitad del siglo XVIII en Barcelona", Congreso Internacional "Imagen y Apariencia", Murcia, 2008 y "La casa a la Catalunya del Set-cents: aproximacions als materials d'estudi", ornades internacionals "Espais interiors", Casa i art, Barcelona, 2006.

8 Crespo Rodríguez, M. ${ }^{a}$ D.: Arquitectura doméstica de la Ciudad de los Reyes (1535-1750), Sevilla, Diputación Provincial de Sevilla, Servicio de Publicaciones, 2005, p. 322. Franco Rubio, G.: La vida cotidiana en tiempos de Carlos III, Madrid, Libertarias, 2001, p. 119. GARcía FernándeZ, M.: "El patrimonio doméstico 
igualmente Rodríguez Bernís, Reynies y Pallot ${ }^{9}$. Sus reflexiones y aportaciones se irán desgranando a lo largo de las próxima páginas y serán citadas de forma oportuna.

La limitación en el número y aparición de los inventarios post-mortem genera, en ocasiones, algunas distorsiones en los procesos de análisis de la penetrabilidad del canapé en los hogares burgaleses del Setecientos, en el número de piezas habidas y en las tasaciones de dicho mobiliario, circunstancias que generan, de tanto en tanto, algunas dubitaciones, inquietudes y dislocaciones en las reflexiones vertidas en estas páginas. Empero, las tendencias generales son, desde mi modesto entender, preclaras, lúcidas, creíbles y hasta digeribles sin excesiva acidez.

Un asunto esencial, en efecto, para evitar suspicacias y reivindicar el mayor grado posible de cientifismo para este estudio sobre la cultura material en el siglo XVIII, con una probada carga de experimentación y la capacidad de repetir reiteradamente el mismo ejercicio documental, es establecer qué credibilidad, fiabilidad y representatividad tienen los documentos y la base matemática en la que se sustentan las reflexiones que se ofrecen en estas páginas. De la contemplación del CUADRO I se obtiene la percepción de a qué situaciones nos enfrentamos. Con entre un 75 y un 100 $\%$ de representatividad se encuentran la nobleza rentista y gobernante $(100 \%)$, los tenderos y profesionales del derecho - procuradores del número y abogados - 80.1 $\%$ ) y las dignidades y canónigos catedralicios (77.8 \%). Entre un 25 y un $75 \%$, los comerciantes $(56.2 \%)$, los profesionales de las administraciones eclesiásticas $(52.8$ $\%)$, los escribanos del número y Su Majestad (50.1\%), los empleados en la administración de Hacienda (36.9 \%), los hortelanos (32.1\%) y el clero como categoría socioprofesional, exceptuados como sabemos los "príncipes" de la Iglesia local. Los eclesiásticos residentes en Burgos han sido "exhumados" en un promedio del 25 al $35 \%$ de los hogares existentes en la ciudad en la época del Catastro de Ensenada.

\footnotetext{
y su simbología. La cultura popular castellana a través del ajuar mobiliario del hogar durante el Antiguo Régimen", Dios, S. de, Infante, J., Robledo, R. y Torijano, E. (coords.): Historia de la Propiedad. Patrimonio Cultural, III Encuentro Interdisciplinar, Salamanca, San José, 2003, p. 77. Germaná Róquez, G.: "El mueble en el Perú en el siglo XVIII: estilos, gustos y costumbres de la elite colonial", Anales del Museo de América, 16 (2008), pp. 193 y 203. Junquera y Mato, J. J.: "Mobiliario", Bartolomé Arraiza, A. (coord.): Las artes decorativas en España, Summa Artis, vol. 45, Madrid, Espasa Calpe, 1999, pp. 389-399. Lara Betancourt, P.: "La sala doméstica en Santa Fé de Bogotá. Siglo XIX. El decorado: la sala barroca", Historia crítica, 20

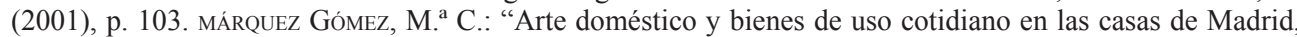
Murcia y Cádiz de don Sebastián Martínez. Un gran mecenas del arte en el Cádiz del siglo XVIII”, Anales de la Real Academia de Bellas Artes de Cádiz, 14 (1996), p. 129. Mateos Gil, A. J.: "La vivienda de don José Raón Cejudo en Calahorra a partir del inventario de sus bienes (1799)", Kalakorikos, 12 (2007), pp. 217, 218, 229 y 234. RodríGuez Bernis, S.: "El mueble tapizado", http://www.ge.iic.com/files/Publicaciones/El_mueble_tapizado.pdf [en línea]. Rotaeche, M. ${ }^{a}$ M., OrdoñEZ, L. y OrdoñEz, C.: "El mueble: su conservación y restauración, Madrid, Nerea, 2007, pp. 54-55. Sampayo Seone, E.: "Un estudio sobre el entorno urbano de La Coruña del siglo XVIII: el ámbito de lo cotidiano", Obradoiro de Historia Moderna, 6 (1997), p. 267. THORNTON, P.: The Domestic Interior, 1620-1920, Londres, Weidenfeld y Nicolson, 1984 y Symonds, R. W.: "English eighteenth-Century furniture exports to Spain and Portugal”, en Burlington Magazine, 455 (1941), p. 57.

9 Rodríguez Bernís, S.: Diccionario de mobiliario, Madrid, Ministerio de Cultura, 2006. Reyniès, N. de: Le mobilier domestique. Vocabulaire typologique, París, Impr. Nationale, 1992, tomos I y II y PALLot, B. G. B.: L'art du siège au XVIIIe siècle, París, A.C.R. Gismondi Editeurs, 1987.
} 


\begin{tabular}{|c|c|c|c|c|c|c|c|c|}
\hline \multirow[t]{3}{*}{ CUADRO I } & \multicolumn{7}{|c|}{ REPRESENTATIVIDAD DE LOS INVENTARIOS POST-MORTEM. } & \multirow[b]{4}{*}{ M2 Hogar } \\
\hline & \multicolumn{6}{|c|}{ BURGOS (A MEDIADOS DEL SIGLO XVIII) } & \multirow[b]{3}{*}{ ÚTIL/AÑO (4) } & \\
\hline & \multirow{2}{*}{$\begin{array}{c}\text { IPM } \\
N^{\circ} \text { Hogares }\end{array}$} & \multirow[b]{2}{*}{$\%$} & \multicolumn{2}{|c|}{ CATASTRO } & \multirow[b]{2}{*}{ \% RIPM (2) } & \multirow[b]{2}{*}{ IPM (3) } & & \\
\hline CAT. PROFESIONALES & & & $\mathrm{N}^{\circ}$ Hogares & $\%$ & & & & \\
\hline HILANDERAS & 17 & 4.6 & 359 & 12.3 & 4.7 & 2212 & 205.5 & 49.9 \\
\hline JORNALEROS & 8 & 2.2 & 260 & 8.9 & 3.1 & 1687 & 288 & 52.6 \\
\hline LABRADORES & 34 & 9.2 & 190 & 6.5 & 17.9 & 12289 & 988 & 209.9 \\
\hline HORTELANOS & 9 & 2.4 & 28 & 0.9 & 32.1 & 4969 & 1432 & 201.4 \\
\hline M/ARTESANOS & 45 & 12.3 & 494 & 16.9 & 9.1 & 17836 & 1476.5 & 136.5 \\
\hline OF/ARTESANOS & 4 & 1.1 & 172 & 5.9 & 2.3 & 7561 & 676.5 & 51.9 \\
\hline COMERCIANTES & 9 & 2.4 & 16 & 0.5 & 56.2 & 147603 & 6700 & 380.7 \\
\hline TENDEROS & 24 & 6.5 & 30 & 1.1 & 80.1 & 87014 & 3093 & 170.7 \\
\hline ESCRIBANOS & 13 & 3.5 & 26 & 0.9 & 50.1 & 94107 & 4325 & 243.5 \\
\hline DERECHO (1) & 16 & 4.3 & 20 & 1.1 & 80.1 & 63111 & 4648 & 472.7 \\
\hline ADMON ECLESIÁSTICA & 19 & 5.1 & 36 & 1.2 & 52.8 & 166162 & 3844 & 237.4 \\
\hline ADMON HACIENDA & 24 & 6.5 & 65 & 2.2 & 36.9 & 130154 & 4187 & 258.1 \\
\hline SERVICIOS PÚBLICOS & 46 & 12.5 & 252 & 8.6 & 18.2 & 35182 & 1493 & 142.5 \\
\hline NOBLEZA RENTISTA & 31 & 8.4 & 29 & 0.9 & 100 & 242462 & 20849.5 & 1068.8 \\
\hline CLERO (TOTAL) & 63 & 17.1 & 190 & 6.5 & 33.1 & 35531 & 4210.5 & 242.7 \\
\hline CLERO BAJO & 5 & 1.4 & 18 & 0.6 & 27.8 & 14003 & 1398 & 149.6 \\
\hline CLERO MEDIO & 34 & 9.2 & 115 & 3.9 & 29.6 & 12138 & 2443 & 169.2 \\
\hline CLERO ALTO & 17 & 4.6 & 47 & 1.6 & 36.2 & 50505 & 7076 & 347.4 \\
\hline DIGNIDADES CATEDRAL & 7 & 1.9 & 9 & 0.3 & 77.8 & 128164 & 14860.5 & 702.9 \\
\hline MILITARES (OFICIALES) & 4 & 1.1 & 74 & 2.5 & 5.4 & 28200 & 2258.5 & 64.2 \\
\hline TROPAS & 3 & 0.8 & 677 & 23.2 & 0.4 & 2760 & 547.5 & 11.5 \\
\hline BURGOS (CIUDAD) & 369 & 100 & 2917 & 100 & 12.6 & & 1496 & 114.1 \\
\hline \multicolumn{9}{|c|}{\begin{tabular}{|l|l|l|l|} 
(1) Derecho: Procuradores del número, abogados, ... & & & \\
\end{tabular}} \\
\hline \multicolumn{9}{|c|}{ (2) Porcentaje de la Representatividad de los inventarios post-mortem sobre el total de hogares del Catastro } \\
\hline \multicolumn{9}{|c|}{\begin{tabular}{|l|l|l|} 
(3) Cómputo total de los inventarios post-mortem (en reales de vellón) & & \\
\end{tabular}} \\
\hline (4) Útil o alcance anual c & e los hogares & (en re & les de vellón) & & & & & \\
\hline
\end{tabular}

El escalón con mayores dificultades de fiabilidad en lo tocante a las reflexiones que sobre ellos se pueden verter es aquel que corresponde a quienes se mostraban remisos, o imposibilitados por "no tener de qué" los escribanos-notarios a levantar acta de sus posesiones y pertrechos - sólo sufrían problemáticas con el reparto de las herencias quienes tenían algo que repartir, poco o mucho, dado que los paupérrimos aseguraban a los descendientes la perpetuación de la miseria y el sufrimiento existencial pero poco más ${ }^{11}-$. Sobre las existencias cotidianas de los profesionales de los servicios públicos (18.2\%), los labradores (17.9 $\%)$, los maestros artesanos $(9.1 \%)$, los militares $(5.4 \%)$, las viudas hilanderas (4.7 $\%)$, los jornaleros (3.1\%), el "proletariado" urbano - léase oficiales artesanos - (2.3 $\%)$ y las tropas acantonadas en las casas y cuarteles de la ciudad (0.4\%), las posibilidades de escribir historia con fiabilidad y credibilidad se reducen mucho, si bien, en su defensa, se ha de decir, que sus IPM presentan una homogeneidad más o menos uniformizada que posibilita efectuar extrapolaciones o generalizaciones creíbles para cada categoría socioprofesional sin excesivas tiranteces ni "errores" de bulto. No sólo

10 Esa es la fórmula habitual utilizada por los párrocos y beneficiados de las parroquias burgalesas para significar por qué no se redactaban últimas voluntades, ni inventarios de bienes, para los fallecidos en la extrema pobreza. Véase, por ejemplo, Archivo Diocesano de Burgos (ADB). San Lesmes. Libro de difuntos. Siglo XVIII.

11 Vid. SAnz de la Higuera, F. J.: “A la sombra de la muerte: viudez espléndida, viudedad paupérrima a mediados del Setecientos", Cuadernos de Investigación Histórica, 22 (2005), pp. 431-461 y "La terrible $\mathrm{f}(\mathrm{r})$ actura de la muerte. Fallecer en el Burgos del Setecientos", Cuadernos de Investigación Histórica, 23 (2006), pp. 251-283. 
nos adentraremos en la escenografía doméstica de las casas-mansión burgalesas sino que entraremos en la inmensa mayoría de los hogares de la ciudad, pobres, modestos o inmensamente opulentos.

El cúmulo de IPM al que, tras arduo rastreo en los Protocolos Notariales, hemos podido acceder, conforma el cuerpo documental sobre el que se ha de trabajar, velis nolis, en la reconstrucción de la historia y de la cultura material. Si dispusiéramos de inventarios post-mortem para toda la población y en diferentes momentos de su ciclo familiar, "todo" sería mucho más fácil. Empero, lo que hay a nuestra disposición es lo poco que la "resaca" en las playas de la historia ha arrojado a nuestros dominios y con ello hemos de urdir, pergeñar, construir, la historia, o las historias, siempre, por supuesto, desde la máxima objetividad, el respeto escrupuloso a la documentación y a sus manipulaciones científicas, y el uso de narraciones matizadas y siempre preñadas de alternativas y sugerencias aceptables y sostenibles ante la comunidad de historiadores, en particular, y los lectores, en general. Hacer historia con las existencias de gentes que no sabían que estaban haciendo historia, es una historia preñada de carencias documentales, problemas metodológicos y tanteos conceptuales que pone en el punto de mira de la crítica más aciaga y destructiva cualquier intento de rescatar lo que presumiblemente ocurrió en el pretérito, remoto o cercano. Son los renglones torcidos del difícil arte de hacer caligrafía histórica con la mano "rota", el cálamo despuntado, la tinta seca y el soporte "quemado". Cualquier historia es posible, pero hay que cuantificarla y escribirla.

\section{CONCEPTO Y ORIGEN DEL CANAPÉ: UN MUEBLE PARA LA ÉLITE}

Al traer a colación la palabra "canapé" ¿de qué estamos hablando? Desde el punto de vista de la historia del mueble, son múltiples las definiciones a procesar y puede ser reiterativo el aportar excesivas entradas. Empero, un surtido racimo de búsquedas nos ayudará a conceptualizar semánticamente el término objeto de estudio, sus peculiaridades y principales características. En 1887, J. Adeline definió "Canapé" como "Asiento grande para dos personas, por lo menos, provisto de respaldo y de brazos" 12 . El canapé, "directo antecesor del sofá", según la brillante expresión de Lara Betancourt, es, a la postre, "un escaño que comúnmente tiene acolchado el asiento y el respaldo para mayor comodidad y sirve para sentarse o acostarse"13, es decir, en la práctica, es un "sofá o diván con el asiento y el respaldo acolchado" que invita a la relajación y la comodidad ${ }^{14}$. El Diccionario de Autoridades (1726) describe un "Banco a manera de los escaños que se usan en España con su respaldo para acostarse o sentarse junto a la lumbre. Diferénciase en que el canapé tiene colchado el asiento y

\footnotetext{
12 Adeline, J.: Vocabulario de términos de arte, Madrid, La Ilustración española y americana, 1887, p. 109.

13 Lara Betancourt, op. cit. (n. 8), p. 103.

14 Glosario de carpintería y ebanistería [en línea]. Véase http://quiminet.com/detalles _artículo.php ?id $=27$
} 
respaldo para mayor comodidad y con dos almohadas para echar encima la cabeza. Es voz Francesa nueva introducida" 15 .

Si vamos más allá, y adoptamos una perspectiva más historicista, hemos de señalar que el canapé es "un sofá de origen francés, cuyo respaldo y brazos laterales se unen en un solo plano de configuración cóncava" que a fines del siglo XVIII pretendió resucitar el gusto por lo clásico ${ }^{16}$. En el siglo XII, en Francia, se llamó conopé y canapé en el siglo XVII. Su significado pasa de las cortinas que rodeaban los lechos al lecho mismo y, poco a poco, va derivando hasta significar un asiento confortable en el que varias personas pueden sentarse y, en caso contrario, puede, incluso, servir de cama. Su trayectoria viene de lejos. El mosquito griego, "kônôps" - no hemos de ocultar el martirio que representan los mosquitos en una habitación, cualquiera que sea la época de la historia humana, no sólo por la picadura en sí cuanto por el insufrible zumbido que produce durante el vuelo. El mosquitero o protección - kônôpeîon, en su versión castellanizada - nos hace vislumbrar la esencia del futuro canapé. En Roma, el "konopeion" acaba derivando en "conopeum" y, más adelante, en la Edad Media y Moderna, en canapeu o cortinas que rodeaban el lecho que, cayendo de un baldaquín aislan una cama ${ }^{17}$.

El canapé fue un mueble con vitola de excepcional, selectivo, poco frecuente y elitista - lo encontramos reflejado en un $16.3 \%$ de los hogares burgaleses del Setecientos -, "constituido por un asiento acolchado, cómodo y elegante que servía para sentarse o reclinarse. En los inventarios aparece [en la América hispana] tardíamente, ya en el siglo XVIII, para salas, estudios y dormitorios. Estaban adornados, como los sillones y las sillas, con ricas telas que les tapizaban (...) con flecos de oro y carmesí, [que otorgaban] a la pieza una elegante vistosidad" "Era un artículo de "buen gusto" que se aclimató entre las grandes familias nobles y "burguesas" de la segunda mitad del Setecientos al hilo de la penetración de modas, a veces frívolas y ligeras, "que querían sacar partido al deleite que proporciona el arte" ${ }^{19}$.

15 Diccionario de Autoridades, Real Academia Española, Madrid, Gredos, 1726/1984, tomo I, p. 106. En la Enciclopedia Universal Ilustrada Europeo Americana, se define "Canapé”, "Del franc. Canapé, del lat. Canapeum, del gr. Konopoion, cama con mosquitero", como "Especie de escaño, que comúnmente tiene rehenchido de cerda o pluma y otras cosas el asiento y respaldo, y sirve para sentarse o acostarse", tomo 11, Madrid, José de Espasa e Hijos, 1911, pp. 25-26. En Monitor, se indica que canapé es un "mueble largo y amplio que sirve para sentarse y que suele tener el asiento y el respaldo tapizado o acolchado para mayor comodidad. Algunos sirven para acostarse. Como todo mueble, hay canapés de muy diversas clases y estilos", Pamplona, Salvat, 1966, tomo 3, p. 42.

16 Véase http://www.deconews.info/txt/glosario/textoglosario.txt [en línea].

17 Véase http://www.tiroalcorcón.com/curio.htm [en línea].

18 Crespo Rodríguez, op. cit. (n. 8), p. 322.

19 Bonet Correa, op. cit. (n. 8), p. 112. La ilusión de la magnificencia y del boato extremo provocó en algunos intelectuales, como por ejemplo Sempere y Guarinos (Historia del lujo, 1788), múltiples críticas sobre la introducción de excesivas novedades. En el balance que hace de los cambios sufridos por los españoles entre el reinado de Fernando VI y Carlos III, afirmaba que "hasta de unos treinta o quarenta años a esta parte (...) los muebles eran costosos, también eran de mayor duración y después de haver servido muchos años se podía aprovechar la materia de que se fabricaban, lo que no sucede con los papeles pintados, con las mesas, taburetes, Canapés y otros muebles que se estilan en el día...". Lo frívolo y lo ligero estaban de moda en una sociedad que quería sacar partido al deleite que proporcionaba el arte. 
Frente al tradicionalismo, a veces obsoleto y triste, de camas, mesas, sillas y bufetes, se añadió una lista de muebles y complementos más funcionales ${ }^{20}$, entre los cuales destacan, dentro del novedoso atrezzo doméstico del XVIII, los muebles de asiento, como los sofás o canapeses, en los que cuidaba, hasta el más mínimo detalle, la decoración, la ebanistería, ... Tal transformación fue, sobre todo, evidente en el estrado, mutado en salón. Las damas pasaron de las almohadas al canapé, revolucionando las formas de cortesía y el uso de las casas, ya que "por primera vez la mujer se sienta igual que el hombre, y ese gesto [aparentemente] intrascendente está carga de [incalculables] consecuencias". "La novedad del canapé -según la brillante reflexión de Lara Betancourt- consistió en dar asiento a tres o cuatro personas al tiempo, promoviendo así la proximidad y por tanto la conversación íntima", a pesar de "su dureza, la ausencia de resortes y de cualquier otro mecanismo de acolchamiento". En todo caso, se popularizó con rapidez, tanto en España como en América ${ }^{21}$.

En resumen, el canapé es un tipo de sofá con respaldo y asiento acolchados de varios cuerpos. De origen francés, comenzó a producirse en el reinado de Luis XIV (1643-1715) y a mediados del siglo XVIII recibieron el influjo del estilo rococó, haciéndose muy exageradas sus decoraciones y dorados. Implantado en primera instancia en las estancias de la Corte gala, fue una herramienta de estatus social y económico para sus dueños, en especial, la aristocracia primero y, después, las "burguesías" de los negocios y de la burocracia, por sus dimensiones y lo complejo de sus diseños y decoraciones. El diván de dos ó tres plazas, generalizado durante el reinado de Luis XIV, servía para estar sentado, no tumbado, aunque fue derivado del lit de repos francés de, aproximadamente 1620 - cuando se puso de moda el que las damas recibieran a las visitas mientras descansaban recostadas en una cama -. En la práctica, el canapé es el resultado de prolongar el sillón de brazos o el de reposo (bergère), y su longitud oscila desde 1 metro hasta algo más de $2^{22}$.

Una variante en el término Canapé es "la silla de bajo respaldo, en madera cincelada y dorada, con patas curvas, asiento y respaldo de rejilla y cojincillo sobrepuesto de tapicería de seda rameada con castillos de flores y guirnaldas", del Museo Lázaro Galdiano, obra francesa, de finales del XVIII ${ }^{23}$, que genera cierta confusión semán-

20 Las estancias se poblaron de mesillas auxiliares, espejos, cómodas, consolas, rinconeras, burós, armarios, etcétera. Véase las reflexiones de Bolufer Peruga, M.: "Lo íntimo, lo doméstico y lo público: representaciones sociales y estilos de vida en la España ilustrada", Studia historica, Historia Moderna, 19 (1998), pp. 85-116. García Fernández, M. y Yun Casalilla, B.: "Pautas de consumo, estilos de vida y cambio político en las ciudades castellanas a fines del Antiguo Régimen. (Sobre algunas teorías del crecimiento económico desde la perspectiva de la demanda)", Fortea Pérez, J. I. (ed.): Imágenes de la diversidad. El mundo urbano en la Corona de Castilla (siglos XVII-XVIII), Santander, Universidad de Cantabria, Servicio de Publicaciones, 1997, pp. 245-282 y GarCía FERnÁNDEZ, M.: "Cultura material y religiosidad popular en el seno familiar castellano del siglo XVIII", Cuadernos Dieciochistas, 5 (2004), pp. 97-121.

21 Lara Betancourt, op. cit. (n. 8), p. 103. Para evitar la miopía de lo localista, y comprobar que las modas y las nuevas tendencias eran generalizadas, Vid. Molina Puche, S. e Irigoyen López, A.: Territorios distantes, comportamientos similares. Familias, redes y reproducción social en la monarquía Hispánica (ss. XIV-XIX), Murcia, Universidad de Murcia, Servicio de Publicaciones, 2009.

22 Salvat Universal, Estella, Salvat, 2006, tomo 6, p. 2417 y ARTEHISTORIA. Grandes Monumentos del Arte. Ficha Alfombras y muebles en http://www.artehistoria.jcl.es/arte/contextos/4692.htm [en línea].

23 Camps Cazorla, E.: Inventario del Museo Lázaro Galdiano, (1948-1950, Madrid, inédito. Vid. http:// www.flg.es/HTML/Obras_2/Canapeosilladebajorespaldo_2323.hmt [en línea] 
tica y conceptual. No negaré su existencia pero mantendré alejada tal posibilidad de las opciones aquí admisibles, al menos para el conjunto predominante de las piezas analizadas - véase la galería de imágenes de la página final -. Es probable, en última instancia, que algunos escribanos, y con ellos los maestros silleros que tasaron los pertrechos domésticos de los difuntos sujetos a inventario, tuvieran en ocasiones problemas semánticos, y técnicos, con la identificación de los canapeses, sitiales y camones, que en algunos IPM son asimilados o incluso confundidos. Eran muebles desconocidos para una gran parte de la población y, en concreto, para los artesanos, en cuyas viviendas de Burgos no se ha detectado la presencia de ninguno.

\section{BURGOS, HOGAR Y CANAPÉ EN EL SETECIENTOS}

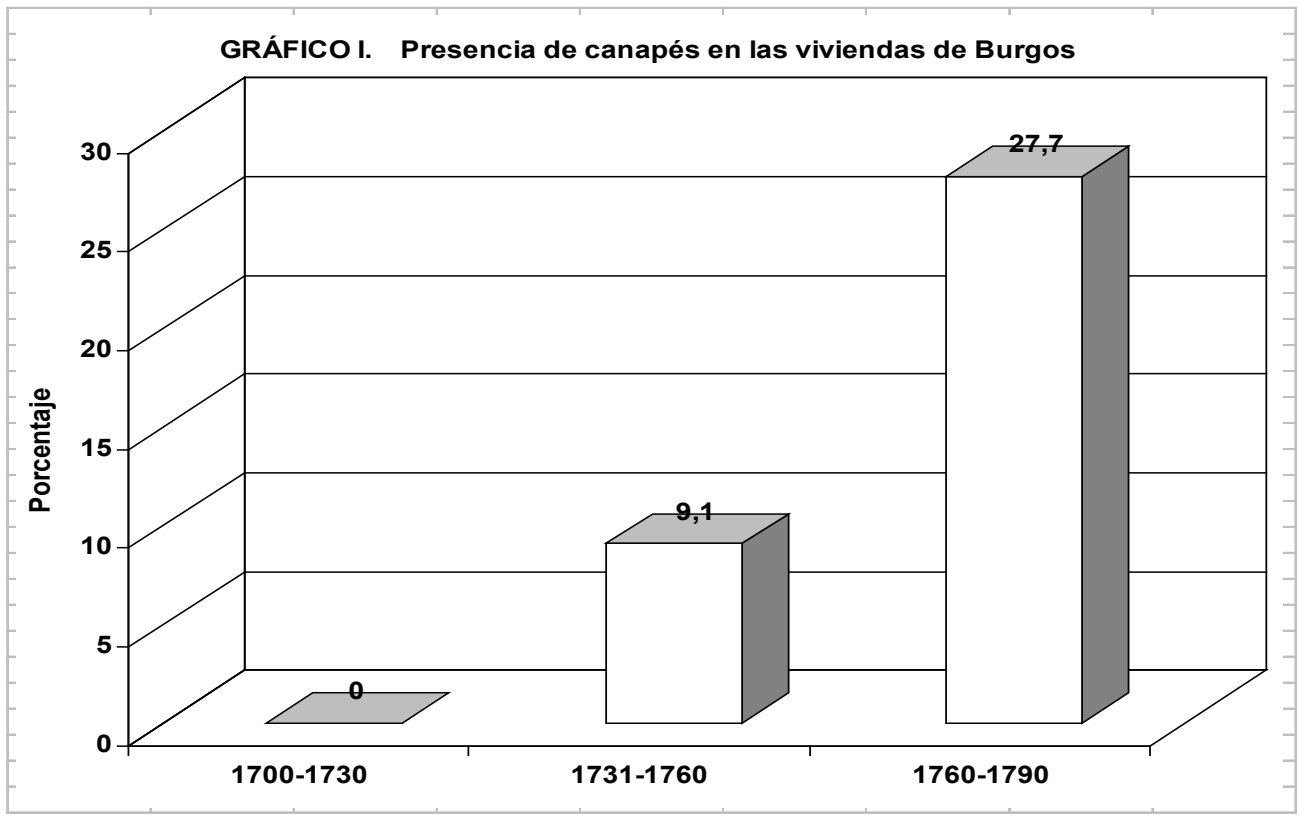

¿Quiénes, cuándo y por qué disfrutaron de canapés - o "Canapeses" - en el Burgos del siglo XVIII? ¿Qué grado de penetración tuvieron y cuál fue la permeabilidad del canapé en la sociedad antiguo-regimental de una ciudad preindustrial, modesta y castellana? ¿Todos los estamentos, estratos y categorías socioprofesionales demostraron similares comportamientos y estrategias ante la colocación del canapé en sus interiores domésticos? ¿Existen rotundas diferencias a la hora de disponer de canapeses en los hogares castellanos? En otras palabras, ¿en qué viviendas encontramos dicho mueble en los inventarios post-mortem (IPM) de Burgos? Para dar una respuesta lo más didáctica y eficiente a tales interrogantes, se esgrimen varias herramientas visuales y estadísticas que irán despejando, gradualmente, las sutilezas de la realidad histórica y su reconstrucción científica. 
La primera constatación general queda plasmada en el GRÁFICO I - con el telón de fondo del CUADRO II como tupida base de referencia habitual -. La sociedad burgalesa del XVIII desconocía a principios del siglo, en el primer cuarto de la centuria, la existencia de los canapeses, dado que en ninguno de los IPM recopilados para ese segmento temporal los escribanos recogieron su presencia en el interior de las viviendas de la ciudad. De una forma tímida y aún balbuciente, en la etapa 17301760 hallamos canapeses en el $9.1 \%$ de los hogares, guarismo que se triplica hasta el $27.7 \%$ en el último tercio del siglo. Con un mayor número de umbrales temporales, descomponiendo la diacronía en segmentos decenales - véase GRÁFICO II -, se observa mejor el proceso de permeabilidad del canapé en Burgos, que hasta 1741 no dio ninguna muestra de estar vinculado a ningún hogar urbano. Dejando al margen el puntual "déficit" estadístico de mediados del Setecientos, se observa que en la década de los 40 a 60 el índice de penetración del canapé era de entre el 10 y el $13 \%$, para crecer, imparable, sostenido e incluso con cierta vertiginosidad en los decenios siguientes $-18.1 \%$ en $1761-1770,34.1 \%$ en la década de los $70,39.1 \%$ en los 80 y un rotundo $66.7 \%$ en los IPM de la década final del siglo -. El espíritu de emulación, la búsqueda de confort y exhibicionismo, la adopción, tardía y muy selectiva, de las modas venidas de Francia al ritmo de la aclimatación de la dinastía borbónica, introducen éste y otros adelantos en las viviendas de Burgos y en sus estancias más sociales y profesionales.

La problemática del cuándo comienzan a aparecer canapeses en los interiores domésticos de Burgos se resuelve al constatar que el primer IPM de entre los recopilados, se elaboró, en 1741, al hilo de la muerte de Diego Huidobro Garoña, un burócrata residente en la calle San Juan, escribano mayor del Real Adelantamiento, quien disponía de "Ocho Canapies [sic] forrados en cabretilla y tachonados de Bronce", tasada cada pieza en 15 reales de vellón ${ }^{24}$. No hemos de olvidar que dicha fecha es la del óbito y, por tanto, desconocemos exactamente desde cuándo, en realidad, tales canapeses residían en el interior de tal vivienda. No descarto, además que haya IPM anteriores a 1741 en que aparezcan canapeses ${ }^{25}$. En Barcelona, al parecer, "no existen referencias documentales anteriores a 1750" 26 . En Zaragoza - ciudad representativa, como Burgos, de un panorama "de provincias" - "encontramos algunos ejemplares localizados en la temprana fecha de 1739 "27.

\footnotetext{
24 Archivo Histórico Provincial de Burgos. Protocolos Notariales - en lo sucesivo AHPB. PN -. Juan Antonio Fernández Guilarte. Leg. 7008 (7 de agosto de 1741), ff. 578-601.

25 La decisión metodológica de utilizar casi con exclusividad IPM de los hogares presentes en el Catastro de Ensenada tiene sus inconvenientes, al obviar algunos de los aparecidos en los períodos extremos del siglo.

26 Piera i Miguel, M. y Mestres i Albert, E.: El mueble en Cataluña. El espacio doméstico del Gótico al Modernismo, Manresa, Angle Edit. 1999, p. 127.

27 Abad Zardoya, op. cit. (n. 7), pp. 388-389.
} 


\begin{tabular}{|c|c|c|c|c|c|c|c|c|c|c|c|}
\hline \multicolumn{2}{|c|}{ CUADRO II } & \multicolumn{9}{|c|}{ Presencia y evolución del canapé en los hogares burgaleses (siglo XVIII) } & \\
\hline & \multirow{3}{*}{\begin{tabular}{|l|} 
Número \\
Hogares
\end{tabular}} & \multicolumn{4}{|c|}{ VIUDAS E HILANDERAS } & \multicolumn{6}{|c|}{ JORNALEROS, LABRADORES y ARTESANOS } \\
\hline & & \multicolumn{4}{|c|}{\begin{tabular}{|l|l|} 
VIUDAS E HILANDERAS \\
Presencia & Número \\
\end{tabular}} & & \multicolumn{3}{|c|}{ Número Presencia } & \multirow{2}{*}{\begin{tabular}{|l|} 
Número \\
Canapés \\
\end{tabular}} & \multirow{2}{*}{$\begin{array}{l}\text {.(1) } \\
\text { PMR }\end{array}$} \\
\hline & & Canapes & $\%$ & Canapés & PMR & & Hogares & Canapes & $\%$ & & \\
\hline $1700-1730$ & 0 & 0 & & & & $1700-1730$ & 0 & 0 & & & \\
\hline $1731-1760$ & 11 & 0 & & & & $1731-1760$ & 11 & 0 & & & \\
\hline $1760-1790$ & 6 & 1 & 16,7 & 1 & 2 & $1760-1790$ & 6 & 1 & 16,7 & 1 & 2 \\
\hline \multirow[t]{4}{*}{ Total } & 17 & 1 & 5,9 & 1 & 2 & Total & 17 & 1 & 5,9 & 1 & 2 \\
\hline & & \multicolumn{3}{|c|}{ COMERCIANTES } & & & \multicolumn{4}{|c|}{ BUROCRATAS } & \\
\hline & Número & Presencia & & Número & .(1) & & Número & Presencia & & Número & .(1) \\
\hline & Hogares & Canapes & $\%$ & Canapés & PMR & & Hogares & Canapes & $\%$ & Canapés & PMR \\
\hline $1700-1730$ & 1 & 0 & & & & $1700-1730$ & 4 & 0 & & & \\
\hline-1760 & 15 & 0 & & & & 173 & 3 & 9 & 27,3 & 7,5 & 215 \\
\hline $1760-1790$ & 17 & 7 & 41,2 & 5 & 128 & $1760-1790$ & 36 & 20 & 55,6 & 5 & 199 \\
\hline \multirow[t]{4}{*}{ Total } & 33 & 7 & 21,2 & 5 & 128 & Total & 73 & 29 & 39,7 & 7,5 & 204 \\
\hline & & \multicolumn{3}{|c|}{ SERVICIO PÚBLICO } & & & \multicolumn{4}{|c|}{ NOBLEZA RENTISTA } & \\
\hline & Número & Presencia & & Número & (1) & & Número & Presencia & & Número & (1) \\
\hline & Hogares & Canapes & $\%$ & Canapés & PMR & & Hogares & Canapes & $\%$ & Canapés & PMR \\
\hline $1700-1730$ & 5 & 0 & & & & $1700-1730$ & 1 & 0 & & & \\
\hline $1731-1760$ & 19 & 2 & 10,5 & 6 & 81 & $1731-1760$ & 14 & 4 & 28,6 & 18 & 455 \\
\hline $1760-1790$ & 20 & 1 & 5 & 6 & 60 & $1760-1790$ & 14 & 9 & 64,3 & 12,5 & 337 \\
\hline \multirow[t]{4}{*}{ Total } & 44 & 3 & 6,8 & 6 & 74 & Total & 29 & 13 & 44,8 & 14,5 & 373 \\
\hline & & \multicolumn{2}{|c|}{ CLÉRIGOS } & & & & & \multicolumn{2}{|c|}{ MILITARES } & & \\
\hline & Número & \multicolumn{2}{|c|}{ Presencia } & Número & .(1) & & Número & \multicolumn{2}{|c|}{ Presencia } & Número & .(1) \\
\hline & Hogares & Canapes & $\%$ & Canapés & PMR & & Hogares & Canapes & $\%$ & Canapés & PMR \\
\hline $1700-1730$ & 16 & 0 & & & & $1700-1730$ & 1 & 0 & & & \\
\hline $1731-1760$ & 28 & 0 & & & & $1731-1760$ & 3 & 1 & 33,3 & 24 & 720 \\
\hline $1760-1790$ & 19 & 3 & 15,8 & 8,5 & 131 & $1760-1790$ & 4 & 3 & 75 & 9 & 157 \\
\hline \multirow[t]{4}{*}{ Total } & 63 & 3 & 4,8 & 8,5 & 131 & Total & 8 & 4 & 50 & 13 & 298 \\
\hline & & \multicolumn{3}{|c|}{ TOTAL CIUDAD } & & \multicolumn{6}{|c|}{ (1) Precio o tasación media en reales de vellón. } \\
\hline & Número & Presencia & & Número &.$(1)$ & & & & & & \\
\hline & Hogares & Canapes & $\%$ & Canapés & PMR & \multicolumn{2}{|c|}{ Fuente documental: } & & & & \\
\hline $1700-1730$ & 32 & 0 & & & & \multicolumn{3}{|c|}{ AHPB. PN. Múltiples legajos. } & & & \\
\hline $1731-1760$ & 177 & 16 & 9,1 & 11 & 290 & & & & & & \\
\hline $1760-1790$ & 159 & 44 & 27,7 & 8 & 201 & & & & & & \\
\hline Total & 368 & 60 & 16,3 & 9 & 225 & & & & & & \\
\hline
\end{tabular}

Si desde la inicial perspectiva general y cronológica descendemos a una óptica más pormenorizada, nos topamos con una realidad que no por muchas veces reiterada, de manera a veces ya tópica y cansina, es posible, ni aceptable, ocultar. La adopción de las mejoras domésticas en el siglo XVIII - en realidad, en cualquier época de la historia - estuvo ligada directamente a los niveles de fortuna y de renta más pudientes y elevados de la ciudad - véase GRÁFICO III - y fue incrementándose con el paso del tiempo y el convulsivo declinar del tictac de los años del siglo. En los hogares humildes únicamente nos topamos con el canapé en el $3 \%$ de los IPM. Los modestos o medianos lo disfrutaban en un $19.3 \%$ de los casos y eran los privilegiados quienes habían dotado a sus estancias con un mobiliario moderno y cautivador, del que el canapé formaba parte indiscutible, en el $37.3 \%$ de sus ocurrencias. 

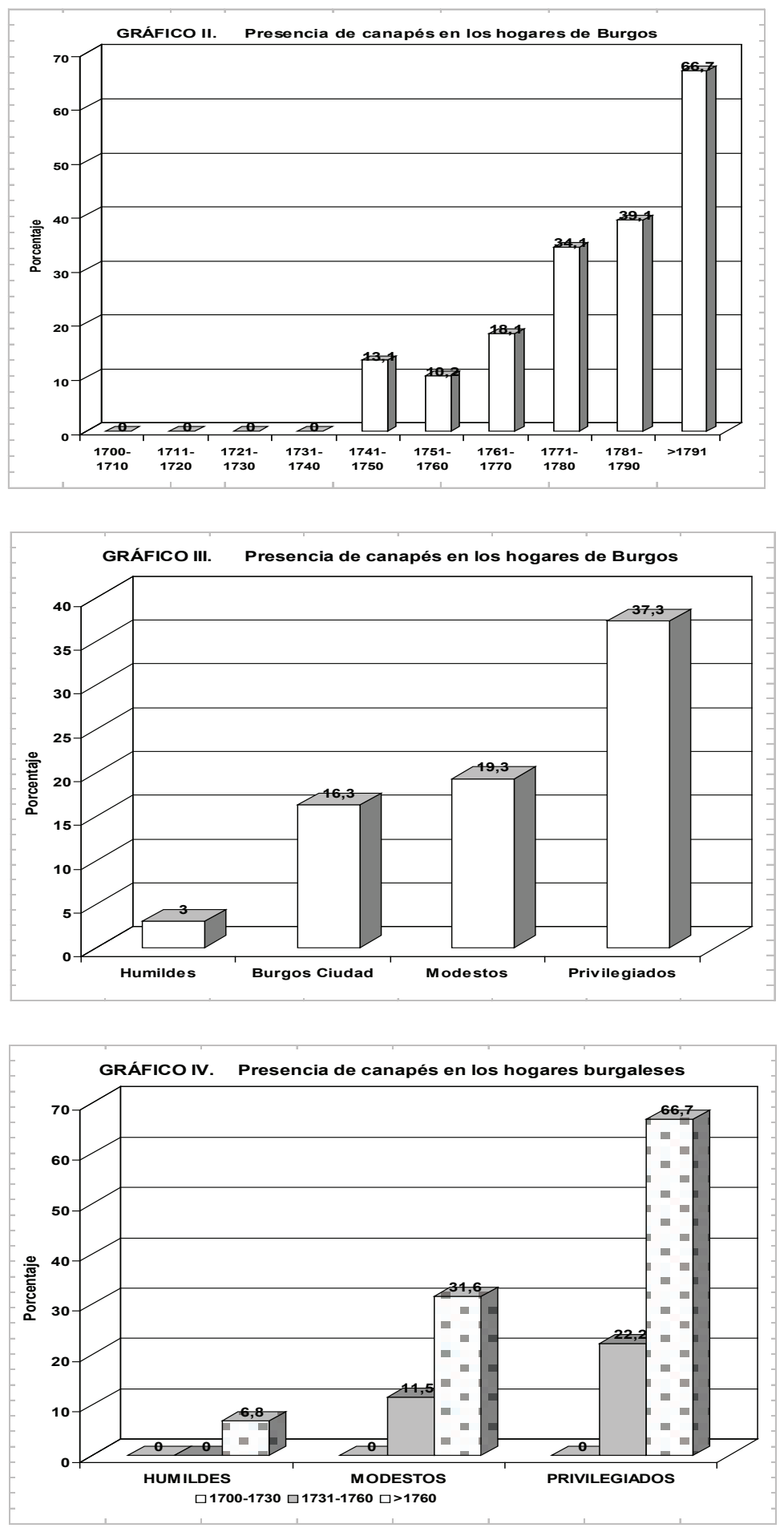
La descomposición de tales porcentajes generales, de la ciudad en su conjunto, en segmentos temporales más específicos nos lleva, a través del GRÁFICO IV, a la constatación indudable de que canapé y riqueza se encuentran indefectiblemente ligados. Los humildes, con un promedio de 4.139 reales en sus inventarios post-mortem, un útil o alcance anual medio de alrededor de 1.700 reales de vellón/año y una disponibilidad monetaria, líquida, en sus talegas, raquítica - contaban con poco más de 250 reales en sus reservas domésticas -, sólo accedieron al canapé en un índice raquítico, el $6.8 \%$ de los hogares, en el último tercio de la centuria ${ }^{28}$. Los modestos o medianos, la mesocracia urbana, con 42.857 reales de promedio en sus IPM, algo menos de 4.000 reales de útil anual y un promedio de dinero contante y sonante discreto, cercano a los 5.000 reales, se fueron incorporando con tibieza al "mundillo" del canapé, desde la más absoluta carencia en el primer tercio del siglo, a un creciente 11.5 y un $31.6 \%$ de $1730-1760$ y 1761-1790, respectivamente. Los privilegiados, aristocracia urbana con un promedio patrimonial cercano a los 150.000 reales, ingresos anuales bastante substanciosos - de alrededor de 25.000 reales - y una cantidad fabulosa de dinero en efectivo, guardado en los cajones de su mobiliario doméstico - de promedio 40.000 reales -, disponían de canapeses en un $22.2 \%$ de las viviendas a mediados del siglo (1731-1760) - no se detecta ninguno al principio de la centuria - y alcanzaron el cenit en el segmento postrero del Setecientos (1761-1790) con el $66.7 \%$ de IPM dotados de canapeses, circunstancia que triplica, con absoluta rotundidad, los porcentajes anteriores. Similares índices se encuentran al abordar otros parámetros de la cultura material, como, por ejemplo, la presencia de libros, relojes ${ }^{29}$, carruajes ${ }^{30}$, cuberterías $^{31}$, en las casas de los burgaleses del siglo XVIII - véase CUADRO III -.

\begin{tabular}{|c|c|c|c|c|c|c|c|c|c|}
\hline \multicolumn{2}{|c|}{ CUADRO III } & \multicolumn{8}{|c|}{ Hogares, canapés, dimensiones y niveles de renta y fortuna. Burgos. } \\
\hline & Total & Hogares con & & Promedio & Útil (1) & & & & \\
\hline Estamento & IPM & canapé & $\%$ & IPM (1) & anual & M2Hogar & $\%$ LIB (2) & $\%$ RELOJ & $\% \mathrm{COCHE}$ \\
\hline General & 142 & 6 & 4,2 & 83.601 & 4.509 & 74.8 & 14,8 & 5,6 & 3,5 \\
\hline Nobiliar & 163 & 51 & 31,3 & 235.109 & 14.305 & 245.9 & 45,4 & 35,6 & 11,1 \\
\hline Eclesial & 63 & 3 & 4,8 & 108.127 & 19.259 & 245.1 & 93,6 & 28,6 & 9,5 \\
\hline \multirow[t]{2}{*}{ Total } & 368 & 60 & 16,3 & 213.609 & 13.573 & 114.1 & 41,8 & 22,8 & 7,9 \\
\hline & Total & Hogares con & & Promedio & Útil (1) & & & & \\
\hline Estrato & IPM & canapé & $\%$ & IPM (1) & anual & M2Hogar & $\%$ LIB (2) & $\%$ RELOJ & $\% \mathrm{COCHE}$ \\
\hline Humilde & 133 & 4 & 3 & 6.541 & 4.112 & 33.7 & 22,5 & 3 & \\
\hline Modesto & 176 & 34 & 19,3 & 119.054 & 2.223 & 173.6 & 48,3 & 27,3 & 3,4 \\
\hline Privilegiado & 59 & 22 & 37,3 & 397.388 & 26.652 & 402.4 & 66,1 & 54,2 & 38,9 \\
\hline \multirow[t]{3}{*}{ Total } & 368 & 60 & 16,3 & 213.609 & 13.573 & 114.1 & 41,8 & 22,8 & 7,9 \\
\hline & \multicolumn{5}{|c|}{ (1) IPM y alcance anual en reales de vellón. } & & & & \\
\hline & \multicolumn{5}{|c|}{ (2) Presencia de libros en los hogares. } & & & & \\
\hline
\end{tabular}

\footnotetext{
${ }^{28}$ Se trata de una humilde viuda, hilandera, Isidora Rosales, cuyo IPM se encuentra en AHPB. PN. Nicolás Martínez Vivanco. Leg. 7147 (23 de diciembre de 1763), ff. 618-632.

29 Sanz de la Higuera, F. J.: "La medida del tiempo en Burgos. Relojes a mediados del siglo XVIII", Historia Social, 67 (2010), pp. 23-49.

30 SANZ de La Higuera, F.J..: "Una estancia doméstica que se mueve. Entre las calles y las casas de Burgos a mediados del siglo XVIII", Cuadernos de Investigación Histórica, 21 (2004), pp. 469-506.

31 Sanz de la Higuera, F.J.: "Aproximación a la mesa de los burgaleses. Cuberterías y platos en el Setecientos", García Fernández, M. (dir.), Cultura material y vida cotidiana: Escenarios, Madrid, Sílex, 2013, pp. 183-195.
} 
La penetración del canapé, y de otros muebles de prestigio, está ligada indefectiblemente, además de a la socioeconomía, al espacio doméstico de las viviendas. El estrato humilde disponía de un promedio poco mayor de $33 \mathrm{~m}^{2}$ de suelos habitables - es decir, de un "quarto" y una cocina, o poco más -, generalmente en concepto de subarrendamiento. Los modestos se albergaban en viviendas con un promedio de $173 \mathrm{~m}^{2}$, en edificios completos o asumiendo en su favor la planta primera, la llamada "noble", de las casas, también en régimen de alquiler pero con bastante amplitud y mayor decoro. Los privilegiados, con un promedio de $402 \mathrm{~m}^{2}$ por hogar, eran, en ocasiones, propietarios y las más de las veces alquiladores de grandes mansiones y edificios de notable envergadura, en cuyo interior ya se había introducido una funcional particularización de las utilidades de cada una de las estancias, con comedores, salas de estrado, oratorios, gabinetes, dormitorios, etcétera, particularmente identificables como tales ${ }^{32}$. En dichas estancias, la aristocracia, en función de las dimensiones de sus bolsillos y de los suelos de sus dependencias, tenía ocasión de colocar canapeses, armarios, cómodas, camas, catres, mesas, etcétera, por doquier.

Un punto de vista más tradicional, merced al concurso de los estamentos del Antiguo Régimen - véase CUADRO III - nos coloca ante guarismos y promedios similares a los ya manejados en los párrafos anteriores, con el añadido de que los clérigos, salvo excepciones, fueron bastante remisos a la penetración del canapé en sus hogares. Los pecheros, caracterizados por sus raquíticos niveles de fortuna y renta, accedieron tarde y en muy escaso número, $4.2 \%$, a la posesión de canapeses, y de libros, y de relojes, y de carruajes, y de ... Padecimientos, eso si, tenían bastantes. En el capítulo carencias y trabajo agotador, estaban servidos en demasía ${ }^{33}$. La nobleza de la ciudad, como extracción social, subida al carro de niveles de renta y fortuna elevados y sostenibles, disfrutaba de canapeses - al $31.3 \%$-,y de libros, y de relojes, y de carruajes, y de ... todo, pues casi nada les era ajena, salvo el esfuerzo laboral y las incomodidades cotidianas. Los eclesiásticos, poseedores de "Librerías" como nadie más en la ciudad - el $93.5 \%$ de los IPM tenían entre sus enseres, pertrechos y menajes domésticos una buena cantidad de libros -, bien dotados, salvo excepciones, de patrimonio y rentas anuales, no demostraron, sin embargo, aunque no todos, apego por las novedades "revolucionarias" en el confort para los interiores domésticos, como la disponibilidad de canapeses en sus viviendas - $4.8 \%$-, que, en la práctica, significaban pérdidas insidiosas en las identidades patrias y caer bajo los dominios de lo extranjero y de lo pecaminoso, del lujo peligroso y contaminante, de la servidumbre bajo fuerzas oscuras - aunque tales perspectivas no tenían efecto en lo tocante al usufructo de relojes ${ }^{34}$-. En el CUADRO III se aprecian también los promedios de las dimensiones de sus hogares. Los pecheros, el estamento general, hacían su vida cotidiana sobre poco más de $70 \mathrm{~m}^{2}$ de espacio habitable útil, mientras que los privilegiados, nobleza y clérigos, rivalizaban en usufructuar alrededor de $\operatorname{los} 245 \mathrm{~m}^{2}$ respectivamente. La disponibilidad de suelo y sus idóneas condiciones socioeconómicas posibilitaron la introducción de mucho mobiliario y un epatante ornato decorativo en

\footnotetext{
32 SAnZ de la Higuera, op. cit. (n. 4), pp. 165-211.

33 García FernándeZ, op. cit. (n. 2), p. 265.

34 SAnz de la Higuera, op. cit. (n. 29), pp. 23-49.
} 
el interior de las viviendas, hasta conseguir un atrezzo doméstico preñado de calidad, de abundancia y de notoriedad.

La permeabilidad del canapé en las viviendas burgaleses del XVIII adoptó unos patrones diferenciales, de contraste, que colocan a cada categoría socioprofesional en el lugar que le corresponde -lamentablemente siempre, al parecer, tendremos pobres y sufridos y sudorosos trabajadores y también ricos que les maltratan y les exploten-. En el CUADRO II se explicitan los porcentajes de presencia, el número medio de canapeses y su valor en reales de vellón. De su análisis, devienen las siguientes consideraciones. Es creíble, a mi entender, una tipificación de las relaciones de los hogares con los canapeses en tres segmentos bastante bien caracterizados. En primera instancia, jornaleros, labradores, artesanos, hilanderas y clérigos. Un segundo estadio en el que se alineaban comerciantes y profesionales de los servicios públicos. Y, en último término, los hogares del "consumir mucho de mucho" ${ }^{35}$, es decir, los nobles rentistas y gobernantes, los burócratas y los militares.

El bloque popular, los del estrato modesto, los del "consumir poco de poco", o "poco de mucho" o "mucho de poco" ${ }^{36}$, los jornaleros, hilanderas, labradores y hortelanos y artesanos, a quien, por razones únicamente de presencia o no de canapeses, se unen los clérigos - dados a consumir bastante de casi todo -, o no accedieron nunca, al menos en el Setecientos, a la posesión de canapeses - es el sesgo de los jornaleros, los campesinos y los artesanos - o lo hicieron muy tarde, a partir de 1761, y con escasa fruición - un $16.7 \%$ en el caso de las viudas hilanderas y un $15.8 \%$ en los hogares eclesiásticos -. Su porosidad ante las modas y las "revoluciones del consumo", ante la penetración del confort y la comodidad, era muy reducida, dado que difícilmente iban a disfrutar del tiempo o dinero necesario e imprescindible para el ocio ${ }^{37}$ y la sociabilidad lujosa, hedonista y exhibicionista. Las viudas, analfabetas, ancianas, hilanderas, cuando habían accedido a tan selecto "club", lo había hecho probablemente en vida de sus cónyuges y el número de piezas, de promedio uno, y la tasación de los expertos, 2 reales, dejan claro qué parámetros les son atribuibles. Los pocos eclesiásticos que disponían de canapé eran, sin embargo, bastante más efectistas, con un promedio de entre 8 y 9 canapeses por hogar y unos precios muy respetables -131 reales de promedio - .

La mesocracia urbana de nivel bajo, los comerciantes y profesionales de los servicios públicos, aunque con muy distintos comportamientos, tienen patrones comunes. Los mercaderes, al por mayor o al por menor, accedieron tarde al lujo de los canapeses pero cuando lo hicieron fue con toda rotundidad - encontramos tal mobiliario en el $41.2 \%$ de los hogares a partir de 1761 -. El número de piezas disponibles, de promedio 5, y su precio, tasados en un promedio de 128 reales, evidencian, junto con la tardanza en incorporarse al canapé, su tibieza y problemáticas ante tal mejora doméstica. Los profesionales de los servicios públicos fueron más precoces pero el grado de penetración del canapé fue reducido, cambiante y poco sostenido. El núme-

35 García Fernández, op. cit. (n. 2), p. 265.

36 García Fernández, op. cit. (n. 34), p. 265.

37 Sanz de la Higuera, F. J.: "Lugares para el ocio en el Burgos del XVIII. Una aproximación socioeconómica", Studia historica, Historia Moderna, 27 (2005), pp. 275-305. 
ro de piezas y su coste, despejan las dudas sobre su talante ante el canapé. Pocos y de baratillo.

La nobleza rentista, terrateniente y gobernante de la ciudad y su Concejo, los burócratas - es decir, la mesocracia urbana de alto rango - y los militares residentes en Burgos, coinciden, aunque con algunas matizaciones, en los procesos y estrategias seguidos ante el canapé. Los aristócratas de extracción nobiliar se incorporaron a su disfrute a partir de la década de los 30 - con un $28.6 \%$ de hogares en que estaba habilitado el uso de algún canapé (nada menos que 18 de promedio y a precios jugosos, de promedio 455 reales) -, pero posteriormente ampliaron su presencia hasta el $64.3 \%$ de los IPM, si bien pasada la euforia de los primeros momentos redujeron el número de piezas - 12 ó 13 en el último tercio del siglo - y su valor decreció un poco - los canapeses de final de la centuria fueron tasados en Burgos en el umbral de los 350 reales - . Los burócratas repiten el sesgo de sus "iguales" nobles pero con los porcentajes y parámetros esenciales más atenuados - véase CUADRO II -. Los militares fueron los más precoces - en el período 1731-1760 gozaban de canapeses en el $33.3 \%$ de las viviendas - y los más "invadidos" de la ciudad - en el último tercio del siglo disfrutaban de canapé en el $75 \%$ de los casos -. El número de piezas y su valor monetario les coloca a medio camino entre el "horror" de los menos afortunados y el boato y la magnificencia de los aristócratas mejor dotados.

Es un hecho sobradamente conocido que la titularidad de muebles en abundancia y de excelente factura, con maderas de gran calidad, está relacionada con el nivel de riqueza y status ${ }^{38}$. Una breve aproximación al número de canapeses en los hogares burgaleses del Setecientos abunda en la misma tesis - véase CUADRO IV -. Aunque se detectan algunas excepciones a la regla, lo usual es que los promedios de número de piezas, niveles de fortuna y renta y las dimensiones físicas de las viviendas crezcan a medida que se incrementa el número de canapeses/hogar. Quienes poseían entre 6 y 15 eran, sin duda, con un promedio de 8 , los hogares predominantes, dado que significan el $76.7 \%$ de los IPM con canapeses en su interior. Sus niveles de fortuna y renta y las dimensiones de los suelos eran muy substanciosos, alejadas de aquellos que únicamente disponían de 1 a 6 piezas, bastante más cercanos a la escasez y las dificultades económicas - que son un $11.6 \%$ de los IPM -. La auténtica aristocracia en la disponibilidad de canapeses se encontraba en los hogares en los que se anotaron más de 16 piezas diferentes, un $11.7 \%$ de los hogares, caracterizados por niveles de renta y fortuna superlativos y escenografías domésticas inmensas, salvo excepciones puntuales. El hogar en que se computaron mayor número de canapeses fue en el de don Miguel Antonio de la Torre y Berna, regidor perpetuo en Burgos y coronel del Regimiento de Infantería Española, quien albergaba en su domicilio 24 canapeses $^{39}$.

38 García González, F., Gómez Carrasco, C. J. y Cebrero Cebrian, M. J.: "Dotes y capitales prematrimoniales. Notas sobre la transmisión de bienes en La Mancha albacetense del siglo XVIII", CHACón JIMÉNEZ, F., Roigé i Ventura, X. y Rodríguez Ocaña, E. (eds.): Familias y poderes, Actas del VII Congreso internacional de la ADEH, Granada, 2006, p. 272.

39 AHPB. Justicia Municipal (JM). Juan Antonio Fernández Guilarte. Leg. 976 (7 de mayo de 1751), ff. 1-29. En el IPM se describen "Quatro fundas de canapeses de damasco por una partte y por la ottra de raso y 8 forradas en Mitán" (120 reales) y "12 fundas de ttercio pelo encarnado para lo mismo a 20 r cada una" (240 reales). 


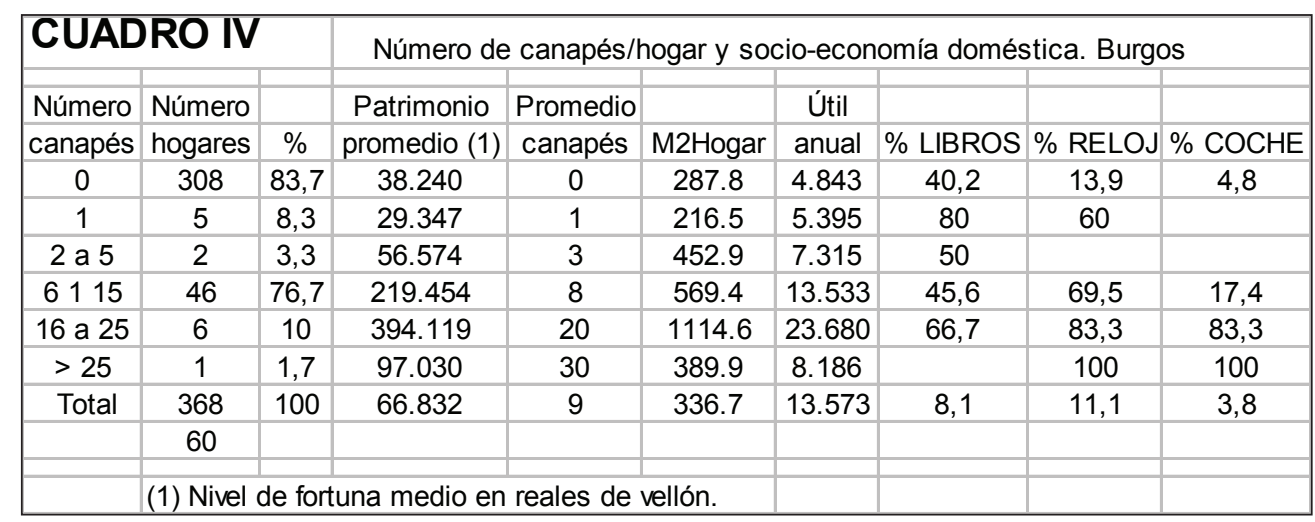

\section{APROXIMACIÓN AL DISFRUTE DEL CANAPÉ EN EL BURGOS DEL XVIII. ALGUNOS MODELOS, SÍNTOMAS DE MODALES Y ESTATUS}

El simple hecho, documental, estadístico, cuantificable y cuantificado, de que no aparezca ninguno en las modestas viviendas de los jornaleros, labradores y hortelanos y maestros y oficiales artesanos, lo dice todo. Aunque siempre hemos de ser conscientes de la limitación de la muestra recopilada, parece creíble afirmar que el canapé difícilmente ocupó sus reducidas y "tuberculosas" habitaciones. Frente a esta rotunda carencia - de hecho, no aparecen canapeses en el $83.7 \%$ de los IPM recopilados -, se van a desgranar en los próximos párrafos algunos ejemplos, no de una manera exhaustiva, para cada categoría socioprofesional, con especial énfasis en aquellos que tengan unas características más definitorias y aleccionadoras ${ }^{40}$.

Entre los comerciantes, descuellan los 6 canapeses "de nogal forrado en lienzo pintado con cubierta de Damasco verde" 41 anotados en el IPM de Manuel Saínz de Viniegra, tasados en 400 reales - ambos miembros del Consulado de Burgos $--^{42}$, los 7 canapeses "forrados de lona" - tasados en 210 reales y ubicados en el "Quarto de

40 Las diferencias profundas entre tipos de colectivos en el Antiguo Régimen en, por ejemplo, las propuestas de análisis de Rodríguez Fernández, D.: "Desigualdades sociales y criterios de consumo diferenciados. Cultura material y nivel de vida en la Galicia interior, Celanova (1630-1850)", Cuadernos Feijonianos de Historia Moderna, 1 (1999), pp. 193-231. Moreno Claverías, B.: "Révolution de la consommation paysanne? Modes de consommation et différenciation sociale de la paysannerie catalane, 1670-1790", Histoire \& Mesure, 21/1 (2006), pp. 141-183 y "Lugar de residencia y pautas de consumo. El Penedés y Barcelona, 1770-1790", Revista de Historia Industrial, 31 (2006), pp. 139-166. SANTIVERI, M.: "Clases sociales y niveles de vida material en la Lleida del siglo XVII (1644-1700)", Manuscrits, 3 (1986), pp. 129-149. GonŹ́LeZ Marcén, P., Montón Subías, S. y Picazo Gurina, M.: "Continuidad y cambio social en la cultura material de la vida cotidiana", Complutum, 18 (2007), pp. 175-184.

41 Vid., entre otras, las reflexiones de García Fernández, M. y Dávila Corona, R. Ma: "Vestirse y vestir la casa. El consumo de productos textiles en Valladolid ciudad y en la zona rural (1700-1860)", Obradoiro de Historia Moderna, 14 (2005), pp. 141-174 y BaRtolomé BaRTOLOMÉ, J. M.: "El consumo de textiles en León (1700-1860)", Revista de Historia Moderna, 21 (2003), pp. 7-61.

42 AHPB. JM. Alonso de Melo Peña. Leg. 987 (1 de julio de 1786), ff. 2-17 y Francisco de Villafranca. Leg. 7098/1 (16 de diciembre de 1768), ff. 17-50. SANZ DE LA HiguerA, F. J.: "Las restauraciones del Consulado de Burgos en el siglo XVIII”, Historia, Instituciones, Documentos, 29 (2002), pp. 429-458. 
entresuelo" - de la vivienda de Rafael de Igarza ${ }^{43}$ y los "Seis canapeses en Madera de Haya de pie de cabra, forrados en Cabretilla" (60 reales), que Alonso Vivar, mercader de chocolate, había dispuesto en la "Sala pral" de su vivienda ${ }^{44}$. En la órbita de los hogares dedicados a la burocracia, y más en concreto a los quehaceres propios de los escribanos del número, brillan con luz propia, Manuel Estefanía y Domingo Ibáñez Varona, junto con el anteriormente citado Diego Huidobro Garoña - estos dos últimos miembros, también, del Consulado y Universidad de mercaderes -. Manuel Estefanía era propietario de "Un Canapé de nogal forrado de Damasco carmesí con funda de lienzo pintada y con pie de cabra tallado", de $2 \frac{1}{2}$ varas de largo (2.075 metros), tasado en 360 reales, que estaba dispuesto en la "Sala pral a la calle de San Juan", estancia que haría las veces, alternativamente, de comedor diurno y dormitorio nocturno. Además, en la "Sala pral al jardín" - quizá también con funciones de comedor, sala de estar y dormitorio -, el escribano había colocado "dos canapeses de paja que forman uno con seis asientos", fabricado en haya y pino y "dado de color de café", evaluado en 44 reales ${ }^{45}$. Por su parte, Domingo Ibáñez Varona sentaba a las visitas, o se acomodaba en la intimidad con su familia, en "Seis Canapies [sic] de estrado forrados de terziopelo con clavazón dorado", tasados en 120 reales, ubicados en el denominado "Quarto $2^{\omega}$ " o sala principal de la casa, según la expresión del escribano Villafranca, autor del IPM ${ }^{46}$.

También entre los burócratas, pero en esta ocasión, en las filas de los abogados y procuradores del número, sobresalen las ocurrencias del IPM de Pedro Campos, Blas Álvarez Castañeda y Domingo Ortuzar. Las descripciones aparecidas en casa de Campos son realmente cautivadoras. "Seis ganapeses" de $3 / 4$ de vara (0.6 metros) por $1 / 2$ vara (0.41 metros), "forrados en Badana encarnada y guarnecidos con galón de seda y tachuela dorada con la cubierta de alfombrilla verde y otros colores" tasados en 120 reales - y otros cuatro similares, de las mismas medidas y $1 / 3$ de alto, "forrados en Badana encarnada, guarnecidos con galón de lana y tachuelas doradas" (56 reales)" "47. Lamentablemente en este IPM no se detallan las estancias de la vivienda. No ocurre lo mismo, por fortuna, en casa de Blas Álvarez Castañeda, en cuya sala principal o dormitorio reposaban "Seis Canapeses de Haya, forrados de Valdés encarnado, con sus fundas de Damasco y cubiertas de Cottón", tasados en 144 reales $^{48}$. La misma perspectiva se contempla en lo tocante a Domingo Ortuzar. "Seis ganapeses en Haya, Torneados, forrados en Baqueta" (72 reales), ubicados en el "Quarto del Salón que cae a San Gil", en la práctica sala de estrado, gabinete de trabajo y dormitorio secundario ${ }^{49}$.

Los profesionales de las administraciones eclesiásticas tuvieron en don Pedro Tomé González a uno de sus principales adalides en el devenir del Setecientos. Los 16 canapeses que se detallan en su IPM se encontraban diseminados por las distintas

\footnotetext{
43 AHPB. PN. Feliciano Medel de Prada. Leg. 7259/4 (28 de julio de 1787), ff. 99-117.

44 AHPB. PN. Feliciano Medel de Prada. Leg. 7258/2 (28 de septiembre de 1781), ff. 242-306.

45 AHPB. PN. Francisco Sanz Escolar. Leg. 7238 (17 de mayo de 1788), ff. 37-48.

46 AHPB. PN. Francisco de Villafranca. Leg. 7086 (22 de abril de 1747), ff. 229-256.

47 AHPB. PN. Nicolás Martínez de Vivanco. Leg. 7147 (6 de febrero de 1763), ff. 141-182.

48 AHPB. PN. José Arcocha. Leg. 8315 (25 de abril de 1770), ff. 23-36.

49 AHPB. PN. Ángel Arnaiz. Leg. 7171 (15 de septiembre de 1772), ff. 218-245.
} 
estancias de la gran mansión que albergaba a su dilatado y múltiple hogar. En el " 3 " Quarto de escusa", entre las dependencias de la $1^{\text {a }}$ casa, probablemente usufructuado como comedor, se alojaban " 6 canapeses torneados de nogal, forrados de terliz" de 1 vara de largo ( 0.83 metros) por $1 / 2$ vara de ancho ( 0.41 metros) - a los cuales se dio un valor de 96 reales -, en el "Recibidor", junto a una estrambótica colección de armas, se hallaban colocados "Siete canapeses torneados de nogal, forrados de terliz", de idénticas dimensiones que los anteriores y tasados en 122 reales y, a la postre, "Tres Canapeses de nogal, torneados, forrados en terliz", de las mismas dimensiones y con un precio bastante inferior, 48 reales, ubicados en el "Quarto $2^{\circ}$ de la Contaduría", en la segunda casa controlada por los Tome-Carrera. Aunque no se detalla en dónde reposaban, Josefa Carrera disponía de "Catorze cubiertas de Canapeses de tafetán de franzia, uniforme a las cortinas" (168 reales), "Nueve (...) [del mismo género] guarnecidas en felpilla" (108 reales) y 6 más "de terciopelo encarnado para Canapeses en galón de [ilegible] y forradas de Mitán verde", tasadas en 60 reales $^{50}$. María Espina de Velasco, viuda del también, en su momento, mayordomo del Cabildo catedralicio, como Tomé, disponía de "Ocho canapeses de pie de cabra, pintados de Azul" (160 reales), que la viuda tenía dispuestos al fallecer en el "Quarto pral ó Quarto del Relox" - a la sazón, estrado y dormitorio -. Este mobiliario estaba decorado con "Seis cubiertas para Canapés de Damasco Carmesí, guarnecidas con franja de seda del mismo color" (72 reales) y otras dos más bastante maltratadas (6 reales) $)^{51}$.

Burócratas al fin, aunque en el ramo de lo civil y alineados en la Administración General de Rentas Reales - léase Hacienda -, descuellan sus máximos responsables, José Castilla y Portugal, por una parte, y don Félix Sánchez de Valencia, por otra -. Don José vivía confortablemente y era propietario de "Seis Canapés de Haya, forrados de cabretilla" (66 reales), colocados en el "Salón a la calle" y "Un Camón de Nogal, forrado de Damasco" (420 reales) que don José tenía habilitado en el "Quarto de Estrado" 52 . En casa de "Don Phelix" lucían, también en el estrado, "Seis sitiales con los pies torneados, forrados de badanilla" (240 reales) y "Un Camón de nogal, forrado de Damasco", evaluado en 360 reales $^{53}$. No menos importante es el escenario doméstico de don José Antonio Gonzalo del Río, administrador también de las Rentas Reales, mercader de notable abolengo, miembro del Consulado y Director de la Real Compañía de comercio de Burgos. En sus múltiples estancias se descubren 14 canapeses, en especial los 12 de pie de cabra, forrados en lienzo encarnado y tasados en 264 reales, que estaban dispuestos en su gabinete de trabajo ${ }^{54}$. Por otra parte, bastante más discreto, en las casas de los profesionales de la sanidad, entre las "gentes" de los servicios públicos, aparece Alfonso López Momediano, boticario,

\footnotetext{
50 AHPB. JM. Juan Antonio Fernández Guilarte. Leg. 977 (14 de julio de 1764), ff. 21-127.

51 AHPB. JM. Alonso de Melo Peña. Leg. 987 (19 de junio de 1780), ff. 1-106.

52 AHPB. PN. José Guadilla. Leg. 7132 (30 de octubre de 1786), ff. 525-569.

53 AHPB. PN. José Guadilla. Leg. 7131 (27 de febrero de 1778), ff. 725-780.

54 AHPB. PN. Nicolás Martínez de Vivanco. Leg. 7150 (3 de diciembre de 1768), ff. 138-189. Véase el anteriormente citado SANZ DE LA Higuera, op. cit. (n. 42), pp. 450-453.
} 
dueño de "Seis Canapeses de nogal, torneados, con asientos de Valdés encarnado" $(90 \text { reales })^{55}$.

La nobleza rentista tenía en don Fernando de Salamanca, don Cayetano de Arriaga, don Felipe Antonio de Salamanca - ambos miembros, igualmente, del Consulado - y en doña Antonia Casilda del Río y San Martín o doña Margarita Guerra, sus mejores exponentes en este orden de la posesión de canapeses. El denominador común es, salvo excepciones, el número 18 y la calidad y elevados precios de las piezas mostradas en sus casas-mansión. Don Fernando de Salamanca disponía de 18 canapeses con 18 cubiertas de Damasco carmesí, guarnecidos en seda dorada - tasado todo en 504 reales $-{ }^{56}$. Cayetano de Arriaga había colocado "Doze Canapeses de haya torneados, forrados en cabretilla encarnada" (180 reales) en los "Quartos prales a la calle Juego de Pelota" - léase estrado - ${ }^{57}$. Don Felipe Antonio de Salamanca y Moreda había apostado por un "Canapé con cubierta de Indiana o cottón" (150 reales) y "una Commoda ó Camón de Madera dorada, forrada en Damasco carmesí y claveteada con tachuelas doradas con tres almoadones o colchincillos de Damasco carmesi", una auténtica joya mobiliaria de 1.100 reales de vellón ${ }^{58}$. Doña Antonia Casilda era titular de 18 canapeses forrados en cabretilla encarnada con pies torneados (216 reales), sobre los cuales se asentaban 12 cubiertas de canapeses de Damasco encarnado con forro de seda del mismo color (144 reales) y 6 cubiertas más con forro de seda de Francia (54 reales) ${ }^{59}$.

En las filas del clero, despuntan con luz propia don Juan Francisco Guzmán y don Ramón de Larrínaga y Arteaga, en la práctica los únicos eclesiásticos para quienes se han encontrado canapeses. Eran, sin duda, dignidades y canónigos de marcado sesgo "progresista" y modernizador. El Capiscol Guzmán era usuario de "Un Canapé grande ó Camón de Nogal, forrado en Damasco, maltratado, con cubierta de Lienzo Pintado", que se encontraba ubicado en el "Quarto Pral" - dormitorio del clérigo - ${ }^{60}$. Don Ramón, por su parte, era propietario de "Un canapé de Madera de Haya grande [de 9 pies (2.9 metros) de largo por 2 pies ( 0.7 metros) de ancho] de pie de cabra forrado de cabretilla", que el Abad de San Quirce tenía alojado en la "Sala prinzipal" - su dormitorio - y de "Un Camón ó Canapé [de 8 pies (2.6 metros) de largo por 2 pies (0.7 metros) de ancho] forrado en Valdés Encarnado con fleco de Seda color perla" (80 reales), colocado en el "Quarto Oratorio" 1.

Para terminar, una breve referencia, de nuevo, a los militares. El ya citado anteriormente don Miguel Antonio Torre compartía con el brigadier don Juan Manuel de Burgos y con el marqués de Lorca las veleidades de las nuevas modas escenográficas en los interiores domésticos del Burgos del siglo XVIII. El que fuera coronel

55 AHPB. JM. Andrés Miguel Varona. Leg. 928 (1758), ff. 22-73. En esa misma línea, Manuel Pérez de Limpias, AHPB. PN. Gaspar Tomé González. Leg. 8312 (21 de enero de 1760), ff. 38-90 y Manuel Cortés Moreno. José Guadilla. Leg. 7131 (14 de octubre de 1780), ff. 913-932.

56 AHPB. PN. Jacinto del Río. Leg. 7055/2 (15 de octubre de 1760), ff. 124-157.

57 AHPB. PN. Francisco de Villafranca. Leg. 7096/2 (31 de enero de 1765), ff. 21-64.

58 AHPB. PN. José García. Leg. 7132 (8 de julio de 1782), ff. 689-709.

59 AHPB. PN. Andrés Miguel Varona. Leg. 7207 (27 de octubre de 1769), ff. 688-705. Vid. también, Margarita Guerra en AMB. Leg HI-5178 (15 e noviembre de 1779), ff. 1-38.

60 AHPB. JM. Alonso de Melo Peña. Leg. 987 (16 de septiembre de 1778), ff. 1-38.

61 AHPB. PN. Jacinto Álvarez. Leg. 7268 (9 de diciembre de 1773), suelto. 
del Regimiento de Milicias de Burgos y, posteriormente, brigadier (general) de los Reales Ejércitos - casado con la susodicha doña Margarita Guerra, viuda a su vez del Intendente de los Reales Ejércitos y miembro del Consejo de Su Majestad don Andrés Pérez Bracho -, vivía con un notable confort y comodidad. En ello influían los 14 canapeses que tenía desplegados por su enorme vivienda. "Seis Canapeses de Nogal, con cubiertas de tela de nube y fundas de tafetán verde" (132 reales), "Dos Canapeses de pie torneado, forrados en tela de Nube con sus fundas de tafetán ver$d e "$ (32 reales), ubicados en el "Quarto pral a calle de Trascorrales" - dormitorio secundario - y otros 6 canapeses más, "de nogal, pie de Cabra, en blanco, forrados de Cabretilla y cubiertos de anubadas" (72 reales) en los "Quartos prales a Huerto del Rey" - dormitorio principal $-{ }^{62}$. Don Francisco de Castro y Cárdenas, marqués de Lorca, gentilhombre de Cámara de Su Majestad, capitán de granaderos del Regimiento de Granada y miembro del Consulado de Burgos, era algo más modesto y se le atribuyen, a la hora de su óbito, "Siete Canapeses de nogal torneados [de 3/4 de vara ( 0.6 metros) de largo por $1 / 2$ vara ( 0.4 metros) de ancho cada uno] (70 reales), los cuales podían ser cubiertos con 5 forros de damasco encarnado (15 reales) ó 6 de terciopelo (60 reales). Dichas piezas se hallaban alojadas en los "Quartos prales" estrado y dormitorios ${ }^{-63}$.

\section{UNA BREVE APROXIMACIÓN A LAS MADERAS DEL CANAPÉ}

¿Eran los canapeses muebles con peculiaridades diferenciales con respecto a otros mobiliarios para sentarse? A juzgar por la perspectiva definida en el CUADRO V, el canapé era armado primordialmente, al igual que las sillas, con nogal - ocurría en el entorno del 52-54\% de las unidades -, pero diferían sensiblemente, y ahí está su peculiaridad más significativa, en el uso del haya para el canapé - el $43.3 \%$ de ellos estaba dotado con un esqueleto procedente de dichos árboles - y del pino para las sillas - el $42.3 \%$ de ellas fue confeccionado con el más modesto pino -. Las sillas de haya eran casi inexistentes ( $2.6 \%$ de las unidades recopiladas) mientras que los canapeses de pino en poco se dejaban sentir (1.6\%). Además, como se ha señalado a lo largo de las anteriores páginas, las telas y materiales textiles que envolvían su interior de madera eran mucho más ricas y de calidad que los más groseros aposentos de las sillas, en especial en lo tocante a su procedencia, en su mayoría importadas desde Francia - descuellan los forrados de damasco, Valdés, indianas (algodón), tafetán, ... -. Un auténtico festín de la exhuberancia para los interiores domésticos, con salas de estar, estrados, oratorio o gabinetes de trabajo, preñados de luz y color ${ }^{64}$.

62 AMB. José Sainz de Quintanilla. Leg. HI-5178 (15 de noviembre de 1779), ff. 1-38.

63 AHPB. PN. Francisco de Villafranca. Leg. 7095 (17 de marzo de 1763), ff. 298-351. Sobre los Castro y Cárdenas véase Sanz de la Higuera, F. J.: "De Burgos a El Puerto de Santa María. El futuro profesional de la nobleza de provincias. Los marqueses de Lorca en el Setecientos”, Trocadero, 20 (2008), pp. 199-215.

64 Vid. Sanz de la Higuera, F. J.: "Luz y color a raudales. Vidrieras en los interiores domésticos. Burgos en el Setecientos", ASRI, Arte y Sociedad, Revista de investigación, 2 (2012). 


\begin{tabular}{|c|c|c|c|c|}
\hline CUADRO V & \multicolumn{4}{|c|}{ Maderas de los canapés y las sillas en las casas de Burgos } \\
\hline MUEBLE & NOGAL & HAYA & PINO & OTROS \\
\hline CANAPÉ & 52.6 & 43.3 & 1.6 & 2.5 \\
\hline SILLAS & 54.4 & 2.6 & 42.3 & 0.7 \\
\hline & Todos los datos en porcentaje & & \\
\hline
\end{tabular}

\section{A MODO DE CONCLUSIÓN}

La disponibilidad de canapeses en los escenarios domésticos burgaleses, en los interiores de los hogares del Burgos del Setecientos, fue, como en otros parámetros de la cultura material, un vector muy restringido y elitista, exótico y selectivo, al que únicamente tuvieron acceso, en un devenir creciente y sostenido, un reducido porcentaje de la población, de las familiares albergadas en su casco urbano. Las dinámicas de flujo de penetración, de permeabilidad de los canapeses en los hogares, respondieron a la materialización de estrategias de consumo conscientes, propias de una sociedad muy diferencial y extremadamente distribuida, preindustrial y aún de Antiguo Régimen. En función de los niveles de renta y fortuna, del rango y la confortabilidad, algunos hogares, pocos, fueron añadiendo pertrechos y enseres que multiplicaban la comodidad y el virtuosismo en sus estancias domésticas y potenciaban la exhibición de sus estatus y la constatación de sus inmensas potencialidades. Estaban a las puertas de una transformación radical de la Edad histórica y del modo de producción predominante y de una "revolución del consumo" impetuosa y trepidante que iba a cambiar, a veces de manera muy vertiginosa, la faz de la Tierra hasta entonces conocida.

El canapé constituye una "delicatessen" en madera y telas de calidad para los interiores domésticos, un lujo urbano al alcance de muy pocos hogares. Una escueta aristocracia del residir urbano abrió sus puertas al mundo, en especial a Francia, a su colorido y desbordante barroco y rococó, e inundó sus estancias de formas y maneras inusitadas y "revolucionarias". El resultado de prolongar el sillón de brazos o el de reposo ("bergère") posibilitaba, con una longitud desde un metro a algo más de dos, implementar en los salones de las viviendas receptáculos con múltiples respaldos o con un único respaldo prolongado, brazos en sus extremos y una maravillosa tapicería, en los que dar rienda suelta a la sociabilidad, a la confortabilidad, a la comodidad, a la intimidad, a la individualidad, según fueran prescindibles o imprescindibles.

En efecto, los estilos Luis XV y Luis XVI nutrieron los salones de las Cortes europeas, de las grandes mansiones aristocráticas de los titulados y las salas de estar de las más modestas viviendas de los privilegiados de las ciudades pre-industriales, con canapeses en sus diversas variantes. No se trataba únicamente conversar y charlar animadamente. Acabadas las tertulias, el canapé à confidents, con un asiento angular añadido a cada uno de sus extremos, o el canapé à la veilleuse, con respaldo de línea ondulante que se prolongaba en uno de sus extremos hasta englobar parte del asiento, eran, en realidad y después del tumulto, lechos de reposo para la intimidad que, sin solución de continuidad, daban acceso a la confraternización y el despliegue del galanteo y el banquete de los sentidos, en unos momentos u otros. El canapé, con su 
origen francés - desde el reinado de Luis XVI (1643-1715) -, fue aumentando progresivamente, de forma exagerada, sus decoraciones y dorados, daba cuenta del estatus social y económico de sus dueños e incrementaba la vistosidad y confortabilidad de sus asientos y respaldos, acolchados en uno o varios cuerpos. Su deriva en suelo español, e incluso en las bastedad del Imperio, en especial en Las Indias, adquirió la idiosincrasia propia del talante castellano, confraternizando con lo más rancio, con la obsolescencia recia y sólida de siglos anteriores, con la mentalidad más austera y oscura de la versatilidad hispánica, pero con la progresiva adaptación a una especialización de las estancias más decimonónica y capitalista, burguesa y consumista.

El canapé era un bocado de lujo mobiliario (maderas) y textil (telas) colocado en las entrañas de la sociabilidad, la confortabilidad y la exhuberancia de un puñado de hogares modernistas en las ciudades preindustriales del Antiguo Régimen.

Quedan pendientes análisis pormenorizados sobre, en primera instancia, la diferencialidad de las maderas que conformaban las entrañas del canapé en cada una de las categorías socio-profesionales, en segundo término, sobre las peculiaridades de las telas y forros de sus asientos y respaldos (procedencias, precios, ...), en especial en lo referente a la implantación del algodón, y, a la postre, una más intensa descripción de los ambientes o atrezzos de las estancias domésticas en las que se colocaban los canapeses, con la consideración del resto del mobiliario y de los pertrechos artísticos, religiosos, ornamentales, ... que preñaban los interiores habitacionales, fueran abiertos y sociales o más íntimos y, por tanto, opacos a la vista y disfrute de los no residentes. 